\title{
World Bank espouses public health for those in poverty
}

Washington. The World Bank intends to redirect much of the $\$ 350$ million it spends each year towards preventive medicine for the nearly one billion people living in poverty worldwide.

This decision is embodied in a report, Investing in Health, that emphasizes the importance of basic and cheap public health measures not only in helping people live longer happier lives, but also in increasing the productivity of developing countries.

The report argues for doubling or tripling spending on immunization, dietary supplements such as vitamin A and iodine and the prevention and treatment of malnutrition, tuberculosis, maternal deaths, AIDS and other sexually transmitted diseases. The study shows that, since 1950 , such efforts in poor nations have decreased infant mortality by two-thirds and raised the average life expectancy from 40 to 63 years, lifting the economic burden of unhealthy workers and sick or absent schoolchildren in the process.

The benefits of generic rather than brandname drugs, and of lower-level clinics rather than hospitals, are also urged. In some countries, a single teaching hospital can absorb 20 per cent or more of the government's health budget, even though nearly all costeffective interventions are best delivered at lower-level facilities.

But the World Bank warns that its recommendations will probably be opposed by "health workers...drug companies, medical equipment manufacturers and other suppliers" on financial grounds. However difficult to implement, the report marks a reaffirmation by the bank of the importance of health care in economic development.

Susan Greene

\section{EC seeks ban on milk yield hormone}

London. Despite being given the green light by both health and bioethics experts, bovine somatotropin (BST) - the genetically engineered growth hormone that can increase milk production in cattle by up to 20 per cent - is to likely to be banned in Europe for a further seven years.

The European Commission has recommended to the member states of the European Communities that they extend the current moratorium on BST when it expires at the end of the year, arguing that it would be impractical to impose the safeguards that its advisory committees had recommended. This follows a decision three weeks ago by torium on a product that has been fiercely attacked by enviromentalist groups.

Europe's animal health industry has been pushing for the moratorium to be lifted, concerned that it may become a precedent for other decisions restricting the applications of genetic engineering to animalbased products. But various farmers' groups - including Britain's National Farmers' Union - had opposed such a move, arguing that the introduction of BST could lead to a general decline in public confidence in dairy products.

David Dickson the US Senate to impose a 15-month mora-

\section{NIH, FDA seek lessons from hepatitis B drug trial deaths}

Washington. Investigators at the US $\mathrm{Na}$ tional Institutes of Health $(\mathrm{NIH})$ will conduct a thorough scientific review of all patients who have been exposed to the experimental drug Fialuridine before deciding what lessons can be learnt from a small trial of the drug which left two patients dead and four more waiting for liver transplants.

The NIH trial managers were this week meeting representatives of the Indianapolisbased manufacturer Eli Lilly and officials of the Food and Drug Administration (FDA) to discuss details of the Fialuridine trial itself, and the talks were likely to broaden out to deal with the wider implications for trial design for antiviral drugs.

The potential of Fialuridine as a treatment for hepatitis B was first observed when the drug was being tested on 40 HIV patients. It appeared to have a good effect on patients who also had hepatitis B, leading NIH to proceed with a trial last summer in which 24 hepatitis-B patients were treated with the drug for four weeks. More than a third of the patients responded well, encouraging Eli Lilly to pay its developer, Oclassen Pharmaceuticals, \$7.5 million for international rights to the drug, while NIH planned a further, six-month trial this spring.

The first ten patients on this trial began taking the drug in early April. The trial was halted on 26 June after two of them became seriously ill with abdominal pain and nausea and then liver failure. The two patients died earlier this month, and four others have now been referred for liver transplants.

Jay Hoofnagle, joint principal investigator in charge of the trial at the National Institute of Diabetes and Digestive and Kidney Diseases (NIDDK), says it is not clear whether anything could have been done differently to prevent the trial going wrong. "It came on so suddenly", he says. "We realized the drug might be toxic, but we thought that by tracking everything carefully we could watch out for it."

James Balow, clinical director of NIDDK, said that one of the main problems was that the metabolism of antiviral drugs of this type in humans was very different from that in animals. "For many of those drugs, the animal tolerance is just striking - the animals seem to tolerate them without blinking an eye." Safety trials on healthy humans, as required by the FDA, do not necessarily show up a syndrome which, in this case, struck patients with liver problems.

Balow says it is too early to draw any general lesson from this case. "Each of these drugs is very distinctive in its toxicity. A moratorium on trials of this class of drug would certainly be premature."

Colin Macilwain 